\title{
Effects of Biological and Non Biological Agents (Disease Modifying Antirheumatic Drugs) on Bone Mineral Density in a Sample of Rheumatoid Arthritis Patients
}

\author{
Mohammed Hadi Munshed Al-Osami ${ }^{1}$, Omar Farooq Al-Azzawi ${ }^{2}$, Faiq I. Gorial ${ }^{1} \&$ Israa Mohammed Redia $^{3}$ \\ ${ }^{1}$ Rheumatology Unit, Department of Medicine, College of Medicine, University of Baghdad, Baghdad, Iraq \\ ${ }^{2}$ Department of Medicine, College of Medicine, University of Baghdad, Baghdad, Iraq \\ ${ }^{3}$ Rheumatology Unit, Baghdad Teaching Hospital, Baghdad, Iraq \\ Correspondence: Faiq I. Gorial, Rheumatology Unit, Department of Medicine, College of Medicine, University of \\ Baghdad, Baghdad, Iraq. E-mail: faiqig@gmail.com
}

Received: April 7, 2018 Accepted: May 7, 2018 Online Published: May 10, 2018

doi:10.5539/gjhs.v10n6p136 URL: https://doi.org/10.5539/gjhs.v10n6p136

\begin{abstract}
Background: Osteoporosis is an extra-articular complication of rheumatoid arthritis that results in increased risk of fractures and associated morbidity, mortality, and healthcare costs.
\end{abstract}

Objective: To evaluate changes in bone mineral density in a sample of rheumatoid arthritis (RA) patients on biological (anti tumor necrosis factor (TNF) alpha) and non-biological agent disease modifying antirheumatic drugs (DMARDs).

Patients and Methods: A cross sectional study enrolled 60 RA patients diagnosed by rheumatologist according to the 2010 American College of Rheumatology/European League Against Rheumatism (2010 ACR/EULAR) classification criteria for RA. Thirty patient on biological agent (anti TNF alpha) and 30 patient on non-biological agent (DMARD). RA disease-related data wincluded disease duration, disease activity score index of 28 joints (DAS 28) and clinical disease activity index (CDAI), functional class, body mass index and treatment history. vitamin D level were measured in both groups. Bone mineral density was measured by dual energy x-ray absorptiometry of hip and lumber spines for patients. A $\mathrm{T}$-score of equal or less than -2.5 standard deviation that of young healthy adults were taken as osteoporotic and scores between -1 to -2.5 standard deviation was taken as osteopenic.

Results: Prevalence of RA patients on biological agent (anti TNF alpha) who had osteoporosis was $1(3 \%)$ and $12(40 \%)$ were osteopenic, and in patients on non biological (DMARD), Osteoporosis was present in $8(26 \%)$ and osteopenia in 13(43\%, $\mathrm{p}=0.019)$.Vitamin D level in patient on biological agent (anti TNF alpha) was low in $24(80 \%)$ and normal in $6(20 \%)$ patients. While in non biological agent (DMARD) it was low in $13(43.3 \%)$ and normal in $17(56.7 \%)$ of patients, $\mathrm{p}=0.003)$. Patients on biological agent (anti TNF alpha); 15 (50\%) patients showed high calcium, 2(6.7\%) low phosphorous, and 2(6.7\%) high Alkaline phosphatase (ALP) while in patients on non biological agent the results were 10 patients( $33.3 \%$ ) had high calcium, and 5(16.7\%) had high ALP. There was a significant decrease in bone mineral density in RA patients on DMARDS while biological agent (anti TNF alpha) had a role in arrest bone loss in RA patients.

Conclusions: There was a strong association between types of therapy and reduction of bone mineral density.

Keywords: RA, Bone mineral density, Biologics, Non biologic DMARDs

\section{Introduction}

Rheumatoid arthritis is a common systemic autoimmune disease of unknown cause, characterized by a chronic, symmetric, and progressive inflammatory polyarthritis (Zerbini et al., 2016) and it is a frequent cause of secondary osteoporosis (Povoroznyuk et al., 2017) and cause systemic bone loss, reaching $\sim 50 \%$ prevalence of osteoporosis in postmenopausal women (Sapir-Koren etal, 2017). RA is characterized by the development of innate and adaptive immune responses. Auto antibodies and immune complexes collect on joint surfaces where they activate inflammatory processes and contribute to joint destruction in RA_synovitis occurs when leukocytes infiltrate the synovial compartment (McInnes et al., 2011). 
Osteoporosis (OP) is a common complication of inflammatory arthritis such as RA. Although the mechanisms of OP in RA are not fully understood, it is thought that osteoclast and its dysfunction with cytokines that mediated them are the principal pathogenesis factors of this bone disease (Xu et al., 2011). Inflammation has a major contributing role in the development as well as the progression of bone loss in these patients as more severe diseases are associated with greater risk of bone loss. Overexpression of TNF is involved in local bone erosion, and it induces generalized bone loss. Therefore, TNF can be considered as an important link between chronic inflammation and bone loss (Zhang et al., 2010).

Osteoporosis is a systemic skeletal disease characterized by low bone mass and micro-architectural deterioration of bone tissue, with a consequent increase in bone fragility and susceptibility to fracture, fracture related to osteoporosis are estimated to affect around $30 \%$ of women and $12 \%$ of men at some point in developed countries. More than $50 \%$ of adults 50 years of age or older are estimated to have osteoporosis. Of these, almost $70 \%$ are women with postmenapouse osteoporosis (Lee et al., 2011).

Diagnosis of osteoporosis is by dual x-ray absorptiometry (DXA) which is the reference method to measure bone mineral density (BMD) accurately and reproducibly (El-Maghraoui et al., 2007).

This study was designed to evaluate changes in bone mineral density in RA patients on biological (anti TNF alpha) and non-biological DMARDs.

\section{Patients and Methods}

This cross sectional study was conducted on 60 RA patients who were seen at the Rheumatology out patients clinic, Department of Medicine - Baghdad Teaching hospital from July 2013 to July 2014. Thirty RA patients were treated by biological agent (anti TNF alph) and 30 patients on non-biological DMARD (methotrexate). The diagnosis of RA was made using according to the 2010 American College of Rheumatology/European League Against Rheumatism (2010 ACR/EULAR) classification criteria for Rheumatoid arthritis. Patients with histories of chronic disease affecting bone metabolism and endocrine causes, smoking, alcohol were excluded from the study. All female patients were under 50years old (premenopausal) and male under 55. All Rheumatoid arthritis patients were subjected to the following: Body mass index was calculated according to following formula

$$
\text { BMI }=\text { Body weight }(\mathrm{kg}) /[\text { Body height }(\mathrm{m})]^{2}
$$

Bone mineral density measurement of lumber spine and total femur was measured by DEXA machine (Dexxum) 3 , Korean company (osteosys).Blood sample were obtained from all patients the following investigation was done; complete blood count ,Erythrocyte sedimentation rate, Total serum calcium ( $\mathrm{N}=8.4-10.2 \mathrm{mg} / \mathrm{dl}$ ), Total serum phosphorus $(\mathrm{N}=2.3-4.7 \mathrm{mg} / \mathrm{dl})$, Total serum alkaline phosphatase $(\mathrm{N}=40-150 \mathrm{IU} / \mathrm{L})$, Total serum 25-hydroxy vitamin D was measured by ELIZA, The kit was derived from Euroimmun Medizinische Labordiagnostika $\mathrm{AG}$ (Germany). Serum vitamin D level ( $\mathrm{N}=22-42 \mathrm{ng} / \mathrm{ml})$ while level of less than $22 \mathrm{ng} / \mathrm{ml}$ consider low.

\subsection{Statistical Analysis}

Statistical analysis was carried out using SPSS version 20. Categorical variables were presented as frequencies and percentages. Continuous variables were presented as mean \pm standard deviation. Pearson's chi square $\left(\mathrm{X}^{2}\right)$ test was used to find the association between the categorical variables. A p-value of $<0.05$ was considered as significant.

\section{Results}

The mean age of RA patients was $40.70 \pm 9.09$ years old and majority $(50.0 \%)$ of RA patients were aged older than 40 years. The majority (76.7\%) of patients were females. The mean duration of RA was $7.37 \pm 6.51$ years old. The obese patients were $46.7 \%$. The mean vitamin D was $20.92 \pm 3.95 \mathrm{mg} / \mathrm{dl}$ and $61.7 \%$ of patients had low vitamin D. The mean serum calcium was $8.25 \pm 1.12 \mathrm{mg} / \mathrm{dl}$ and $58.3 \%$ of patients had normal calcium. The mean serum

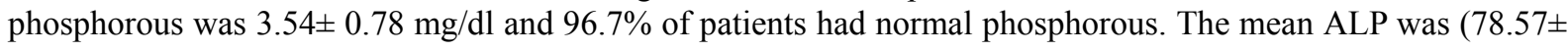
$31.82) \mathrm{mg} / \mathrm{dl}$ and $(88.3 \%$ ) of patients had normal ALP.

The mean DAS 28 score was $4.62 \pm 1.23$ The CDAI mean score was $18.53 \pm 10.20$. Table 1 shows the association of types of therapy with vitamin D, serum calcium and phosphorous as well as ALP. There was significant association between types of therapy with vitamin D. Also there was significant association between types of therapy with total hip score as in Table 2 and there was significant association between types of therapy with Z- total hip score as in Table 3. 
Table 1. Association of types of therapy with vitamin D, serum calcium and phosphorous and ALP

\begin{tabular}{|c|c|c|c|}
\hline \multirow{2}{*}{ Variable } & \multicolumn{2}{|c|}{ Types of Therapy } & \multirow{2}{*}{ P value } \\
\hline & Biology (\%) & DMARD(\%) & \\
\hline \multicolumn{4}{|c|}{ Vitamin D ng/ml } \\
\hline Normal & $6(20.0)$ & $17(56.7)$ & 0.003 \\
\hline Low & $24(80.0)$ & $13(43.3)$ & \\
\hline \multicolumn{4}{|c|}{ Serum Calcium mg/dl } \\
\hline Normal & $15(50.0)$ & $20(66.7)$ & 0.190 \\
\hline High & $15(50.0)$ & $10(33.3)$ & \\
\hline \multicolumn{4}{|c|}{ Serum Phosphorous mg/dl } \\
\hline Normal & $28(93.3)$ & $30(100.0)$ & 0.150 \\
\hline Low & $2(6.7)$ & $0(0.0)$ & \\
\hline \multicolumn{4}{|c|}{ ALP IU/L } \\
\hline Normal & $28(93.3)$ & $25(83.3)$ & 0.228 \\
\hline High & $2(6.7)$ & $5(16.7)$ & \\
\hline
\end{tabular}

DMARDs, disease modifying antirheumatic drugs, ALP, alkaline phosphatase.

Table 2. Association of types of therapy with T- spine and T-Total hip score

\begin{tabular}{|c|c|c|c|}
\hline \multirow{2}{*}{ Variable } & \multicolumn{2}{|c|}{ Types of Therapy } & \multirow{2}{*}{ P value } \\
\hline & Biologics (\%) & DMARD(\%) & \\
\hline \multicolumn{4}{|l|}{ Spine T score } \\
\hline Normal & $16(53.4)$ & $10(33.3)$ & \multirow{3}{*}{0.187} \\
\hline Osteopenia & $10(33.3)$ & $11(36.7)$ & \\
\hline Osteoporosis & $4(13.3)$ & $9(30.0)$ & \\
\hline \multicolumn{4}{|c|}{ Total hip score } \\
\hline Normal & $17(56.7)$ & $9(30.0)$ & \multirow{3}{*}{$0.019 *$} \\
\hline Osteopenia & $12(40.0)$ & $13(43.3)$ & \\
\hline Osteoporosis & $1(3.3)$ & $8(26.7)$ & \\
\hline
\end{tabular}

Table 3. Association of types of therapy with Z-spine score, Z- Total hip score

\begin{tabular}{|c|c|c|c|}
\hline \multirow{2}{*}{ Variable } & \multicolumn{2}{|c|}{ Types of Therapy } & \multirow{2}{*}{ P value } \\
\hline & Biologics (\%) & DMARD (\%) & \\
\hline \multicolumn{4}{|l|}{$Z$ score spine } \\
\hline Normal & $15(50.0)$ & $7(23.3)$ & \multirow{3}{*}{0.094} \\
\hline Osteopenia & $10(33.3)$ & $14(46.7)$ & \\
\hline Osteoporosis & $5(16.7)$ & $9(30.0)$ & \\
\hline \multicolumn{4}{|c|}{ Z score total hip } \\
\hline Normal & $11(36.7)$ & $9(30.0)$ & \multirow{3}{*}{$0.033 *$} \\
\hline Osteopenia & $17(56.7)$ & $11(36.7)$ & \\
\hline Osteoporosis & $2(6.6)$ & $10(33.3)$ & \\
\hline
\end{tabular}




\section{Discussion}

This study showed that patients with rheumatoid arthritis on biological agents (anti TNF alpha) had arrested bone loss while in non-biological (DMARD) showed decrease in bone mineral density. The bone mineral density was significantly associated with types of therapy, which showed non significant decrease in bone loss in RA patients on biological agents (anti TNF alpha). This finding is in agreement with that of Wijbrandts et al. (2009), who found TNF blockade may result in an arrest of general bone loss in patients used infliximab in combination with methotrexate, lumbar spine and femoral BMD remained unchanged Also Large et al. (2005), showed significant BMD increase in femoral neck and on ameliorating trend in the spine in patients with rheumatoid arthritis on infliximab.

Hougeberg et al. (2009), found strong evidence of causal link between inflammation and bone loss in RA patients, anti-inflammatory effects of infliximab was potent enough to arrest inflammatory bone loss at hip but not at the spine and hand. The current study found significant association between RA patients on DMARDS (MTX) and decrease in BMD, this finding agreed with Cranney et al. (2001), who found that BMD of femoral neck did not differ significantly between MTX treated group and RA patients without treatment. Morgan et al. (2004), found in their study that BMD significantly higher in RA patient who did not receive MTX versus those who received MTX.

The current study showed that body mass index showed non statistically significant difference with types of therapy used and $46 \%$ of patients with biological and non-biological DMARD were obese this finding is consistent with the recent finding of Senturk et al. (2013), that anti TNF alpha treatment may have indirect positive effect on lean mass, throughout the general health improvement of patients leading to increase appetite and Briot et al. (2005), who found that Anti TNF agents in inflammatory rheumatic diseases are associated with increase in BMI which result from decrease bone resorption and increase in body weight and lean mass which is observed in parallel with increase in IGF-1 and also found high BMI in MTX treated group attributed to reduction of disease activity (Jurgens et al., 2013).

The current study found a significant association between anti TNF alpha and decrease vitamin D level, this result disagreed with Vacca et al. (2014), who found that in inflammatory rheumatic disease anti TNF alpha agents seem to improve vitamin $\mathrm{D}$ level as well as disease activity but it remained controversial. Low vitamin D in patient with anti TNF alpha in the current study may be due to decrease sun exposure (majority of the females patients are veiled) and may be part of disease activity and long duration rheumatoid arthritis which leads to deformity and immobility. Other explanation is most of patients used NSAIDS that influenced vitamin D metabolism in liver and a recent study showed that there was no overall decrease in bone miniral density associated with low vitamin D level (Vagadia et al., 2011).

In the current study, in RA patients on non-biological DMARD, there is decrease in vitamin D level but not statistically significant decrease, this result agreed with study of Raczkiewics et al. (2013), who found adequate DMARD therapy (without steroid) seem to have beneficial effect on vitamin D level.

In this study, there is non significant changes in calcium, phosphorous, and alkaline phosphatase level in RA patients on biological and non biological agent, which is similar to Torikai et al. (2006) findings. Torikai et al. found non significant decrease in bone markers and no changes in calcium were observed in patient on anti TNF alpha.

In conclusion, there was a significant decrease in bone mineral density in RA patients on DMARDS while biological agent (anti TNF alpha) had a role in arrest bone loss in RA patients. There is no significant decrease in bone mineral density in association with low vitamin $\mathrm{D}$ level.

\section{Competing Interests Statement}

The authors declare that there are no competing or potential conflicts of interest.

\section{References}

Briot, K., Garnero, P., Le Henanff, A., Dougados, M., \& Roux, C. (2005). Body weight, body composition, and bone turnover changes in patients with spondyloarthropathy receiving anti-tumour necrosis factor $\alpha$ treatment. Annals of the rheumatic diseases, 64(8), 1137-1140. https://doi.org/10.1136/ard.2004.028670

Cranney, A. B., McKendry, R. J., Wells, G. A., Ooi, D. S., Kanigsberg, N. D., Kraag, G. R., \& Smith, C. D. (2001). The effect of low dose methotrexate on bone density. The Journal of rheumatology, 28(11), 2395-2399.

El Maghraoui, A., Abayi, D. A. M., Ghozlani, I., Mounach, A., Nouijai, A., Ghazi, M., ... \& Bezza, A. (2007). Prevalence and risk factors of discordance in diagnosis of osteoporosis using spine and hip bone densitometry. 
Annals of the rheumatic diseases, 66(2), 271-272. https://doi.org/10.1136/ard.2006.062372

Funovits, J., Aletaha, D., Bykerk, V., Combe, B., Dougados, M., Emery, P., ... \& Kay, J. (2010). The 2010 American College of Rheumatology/European League Against Rheumatism classification criteria for rheumatoid arthritis: methodological report phase I. Annals of the rheumatic diseases, 69(9), 1589-1595. https://doi.org/10.1136/ard.2010.130310

Haugeberg, G., Conaghan, P. G., Quinn, M., \& Emery, P. (2009). Bone loss in patients with active early rheumatoid arthritis: infliximab and methotrexate compared with methotrexate treatment alone. Explorative analysis from a 12-month randomised, double-blind, placebo-controlled study. Annals of the rheumatic diseases, 68(12), 1898-1901. https://doi.org/10.1136/ard.2008.106484

Jurgens, M. S., Jacobs, J. W., Geenen, R., Bossema, E. R., Bakker, M. F., Bijlsma, J. W., ... \& Utrecht Arthritis Cohort Study Group. (2013). Increase of body mass index in a tight controlled methotrexate - based strategy with prednisone in early rheumatoid arthritis: Side effect of the prednisone or better control of disease activity?. Arthritis care \& research, 65(1), 88-93. https://doi.org/10.1002/acr.21797

Lange, U., Teichmann, J., Muller-Ladner, U., \& Strunk, J. (2005). Increase in bone mineral density of patients with rheumatoid arthritis treated with anti-TNF- $\alpha$ antibody: a prospective open-label pilot study. Rheumatology, 44(12), 1546-1548. https://doi.org/10.1093/rheumatology/kei082

Lee, Y. H., \& Song, G. G. (2011). Efficacy and safety of monthly $150 \mathrm{mg}$ oral ibandronate in women with postmenopausal osteoporosis: a systematic review and meta-analysis of randomized controlled trials. The Korean journal of internal medicine, 26(3), 340. https://doi.org/10.3904/ $/ \mathrm{kjim} .2011 .26 .3 .340$

McInnes, I. B., \& Schett, G. (2011). The pathogenesis of rheumatoid arthritis. New England Journal of Medicine, 365(23), 2205-2219. https://doi.org/10.1056/NEJMra1004965

Morgan, S. L., Chen, D. T., Carlee, J., \& Baggott, J. E. (2004). Effect of methotrexate therapy on bone mineral density and body composition in rat adjuvant arthritis. The Journal of rheumatology, 31(9), 1693-1697.. PMID:15338486

Povoroznyuk, V. V., Grygorieva, N. V., Karasevska, T. A., \& Dzerovich, N. I. (2017). Bone Mineral Density and Trabecular Bone Score Indices in Women with Rheumatoid Arthritis According to the Age and Use of Glucocorticoids. SM Rheumatol, 1(1), 1002.

Raczkiewicz, A., Bachta, A., Kulig, M., Swarowska-Knap, J., Juszkiewicz, A., Kisiel, B., ... \& Tłustochowicz, W. (2013). AB0205 Vitamin d status and its relation with disease activity, disability, treatment schedule, mood and quality of life in polish rheumatoid arthritis patients. Annals of the Rheumatic Diseases, 72(Suppl 3), 849-1136. https://doi.org/10.1136/annrheumdis-2013-eular.2528

Raisz, L. G. (2005). Pathogenesis of Oestoporosis: Concepts, conflicts and prospects. J clin invest., 115(12), 3318-25. https://doi.org/10.1172/JCI27071

Sapir-Koren, R., \& Livshits, G. (2017). Postmenopausal osteoporosis in rheumatoid arthritis: The estrogen deficiency-immune mechanisms link. Bone, 103, 102-115. https://doi.org/10.1016/j.bone.2017.06.020

Senturk, T., Cildag, S., \& Akdam, I. (2013). Effect of anti-tumor necrosis factor-a therapies on weight and body mass index in patients with rheumatoid arthritis and ankylosing spondylitis. Ann Rheum Dis, 72, A875-A876. https://doi.org/10.1136/annrheumdis-2013-eular.2614

Torikai, E., Kageyama, M., Tokahashi, M., et al. (2006). The effect of infliximab on bone metabolism markers in patients with rheumatoid arthritis. Rheumatology, 45(6), 761-764. https://doi.org/10.1093/rheumatology/kei280

Vacca, A., Porru, G., Dessole, G., Mathieu, A., Cormier, C., Fulla, Y., ... \& Allanore, Y. (2014). THU0061 Vitamin D Insufficiency and Deficiency in Two European Cohorts of Patients with Inflammatory Rheumatic Disorders. Annals of the Rheumatic Diseases, 73(Suppl 2), 197-197. https://doi.org/10.1136/annrheumdis-2014-eular.5038

Vagadia, V., Bartholomew, P., Kelly, M., Handley, G., Kelly, C., Bridges, M., ... \& Walker-Bone, K. (2011). Osteoporosis and metabolic bone disease: 73. Do Low Vitamin D Levels Predict Osteoporosis? Rheumatology, 50(suppl_3), iii69-iii74. https://doi.org/10.1093/rheumatology/ker042

Wijbrandts, C. A., Klaasen, R., Dijkgraaf, M. G., Gerlag, D. M., van Eck-Smit, B. L., \& Tak, P. P. (2009). Bone mineral density in rheumatoid arthritis patients 1 year after adalimumab therapy: arrest of bone loss. Annals of the rheumatic diseases, 68(3), 373-376. https://doi.org/10.1136/ard.2008.091611 
$\mathrm{Xu}, \mathrm{S}$., Wang, Y., Lu, J., \& Xu, J. (2012). Osteoprotegerin and RANKL in the pathogenesis of rheumatoid arthritis-induced osteoporosis. Rheumatology international, 32(11), 3397-3403. https://doi.org/10.1007/s00296-011-2175-5

Zerbini, C. A. F., Clark, P., Mendez-Sanchez, L., Pereira, R. M. R., Messina, O. D., Uña, C. R., ... \& Lane, N. E. (2017). Biologic therapies and bone loss in rheumatoid arthritis. Osteoporosis International, 28(2), 429-446. https://doi.org/10.1007/s00198-016-3769-2

Zhang, J., Redden, D. T., McGwin, G., Callahan, L. F., Smith, E. A., Alarcón, G. S., ... \& Mikuls, T. R. (2010). Generalized bone loss as a predictor of three - year radiographic damage in African American patients with recent - onset rheumatoid arthritis. Arthritis \& Rheumatology, 62(8), 2219-2226. https://doi.org/10.1002/art.27510

\section{Copyrights}

Copyright for this article is retained by the author(s), with first publication rights granted to the journal.

This is an open-access article distributed under the terms and conditions of the Creative Commons Attribution license (http://creativecommons.org/licenses/by/4.0/). 